\title{
SUBSIDENCE IN MACEIO, BRAZIL, CHARACTERIZED BY DINSAR AND INVERSE MODELING
}

\author{
P. A. Euillades ${ }^{1}$, L. E. Euillades ${ }^{1}$, P. Rosell ${ }^{1}$, Y. Roa ${ }^{1}$ \\ ${ }^{1}$ Instituto CEDIAC - FI - UNCuyo \& CONICET, Centro Universitario, 5500 Mendoza, Argentina - \\ (leonardo.euillades,pablo.euillades,patricia.rosell)@ingenieria.uncuyo.edu.ar
}

KEY WORDS: Maceió, Sentinel 1 Mission, Salt Mining, SAR Interferometry

\begin{abstract}
:
The city of Maceió has been historically affected by cracks and sink events in buildings and city infrastructure. Availability of a consistent Sentinel 1 Mission dataset between 2014 and 2019 allows characterizing the undergoing crustal deformation process that provokes such effects. We processed a dataset of 81 SAR scenes using the DInSAR-SBAS time-series technique, which allowed us to obtain mean velocity of deformation and deformation time series. Detected displacement patterns show subsidence concentrated in the Mundaú lagoon coast in front of Mutange, Pinheiro and Levada neighbourhoods. Inversion of the results, using analytical models, locates a sill-like source at $\sim 400 \mathrm{~m}$ depth and with a radius of $\sim 0.8 \mathrm{~km}$. Its depth would be compatible with re-activation of the Mutange fault system, possibly related to salt mining operations in the area. Further investigation is needed to better constrain the deformation source and to identify if the observed process was active before the analysed time span.
\end{abstract}

\section{INTRODUCTION}

Multi temporal Interferometric SAR (Synthetic Aperture Radar) processing is a mature technique for characterizing crustal deformation fields in space and time (Hooper et al., 2012). It is based in the availability of SAR scenes acquired along a time span using a consistent acquisition geometry, which means same orbits, sensor modes, and look angles. The range of problems addressed include volcano deformation (Battaglia et al., 2019), earthquake related displacements (Feng et al., 2017), oil and gas production-related uplift/subsidence (Kim and $\mathrm{Lu}, 2018$ ), groundwater extraction related subsidence (Hoffmann et al., 2001), mining-related subsidence (Samsonov et al., 2014), landslides monitoring (Carlà et al., 2019), ice flow velocity measurement (Euillades et al., 2016), among others.

First applications were demonstrated using images taken by the ERS, Radarsat-1 and ENVISAT Missions during nearly two decades between 1991 and 2011. Those missions were programmed to acquire data at user's request, or following a socalled background mission in absence of specific requests. In consequence, series of scenes suitable for long term interferometric processing were not automatically available for a given site of interest. In South America, for example, only a few ERS scenes were taken until 2001, and even after that year, the background missions covered the Andean region but not the coastal one.

The launch of ESA's Sentinel-1A satellite in 2014, followed by the Sentinel-1B one year later, acted as a game changer. Sentinel acquires scenes with global coverage and it is a mission with interferometric application as a main goal (P. Potin et al., 2018). The temporal resolution varies, but in general terms it is 6 days in Europe, and 12 days in other regions. After Sentinel 1 Mission, many sites in South America are regularly covered with SAR acquisitions suitable for interferometric processing. That means that, at some sites, one can characterize deformation processes at relatively high temporal and medium spatial resolution for the first time.
In this work, we use MT-DInSAR and Sentinel 1 data to analyse a deformation process currently ongoing in the city of Maceió, Brazil, between April 2015 and May 2019. We characterize a subsidence pattern affecting the Pinheiro, Mutange and Levada neighbourhoods that would be related to salt mining exploitation. We also inverted the deformation results by using analytical spheroidal and dislocation sources. The modelled location is compatible with documented direct faults that would be either active or presenting signs of re-activation.

\section{AREA OF INTEREST \& DATASET}

The Area of Interest is centered in Maceió, Brazil, at $-9.628^{\circ}$ of latitude and $-35.724^{\circ}$ of longitude. Maceió is the largest city and capital of the state of Alagoas, with almost a million inhabitants within its $511 \mathrm{~km}^{2}$. The city is located between the Atlantic Ocean to the West, and the Mundaú lagoon to the East (Figure 1).

From the geomorphological point of view, the city is built over two different units: the coastal plateau and the coastal plain. The plateau presents topographic height ranging between 20 and 100 $\mathrm{m}$ above sea level. The plains are constituted by fluvial and lagoon deposits related to the Mundaú system, and marine terraces. The transition between both units is abrupt with high sloping areas and cliffs inside the city.

The densely populated neighborhoods of Pinheiro, Mutange and Levada are of particular interest, because they are historically affected by edifices' and roads' cracks and sinking events. These phenomena increased after intense rains and a significant earthquake occurred in February and March 2018, according to the Brazilian Geological Service (CPRM) (Serviço Geológico do Brasil (CPRM), 2019a).

Pinheiro is at the top of the plateau, limiting to the West with Mutange, which is located in the sloping hillside descending to the Mundaú lagoon. Towards the South, Levada is in the plains, also facing the lagoon coast. 
Building problems caught the attention of the CPRM, which began in 2018 an extensive campaign of studies including several techniques as DInSAR, Ground Penetration Radar, gravimetry, seismology, among others. The results are summarized in (Serviço Geológico do Brasil (CPRM), 2019a).

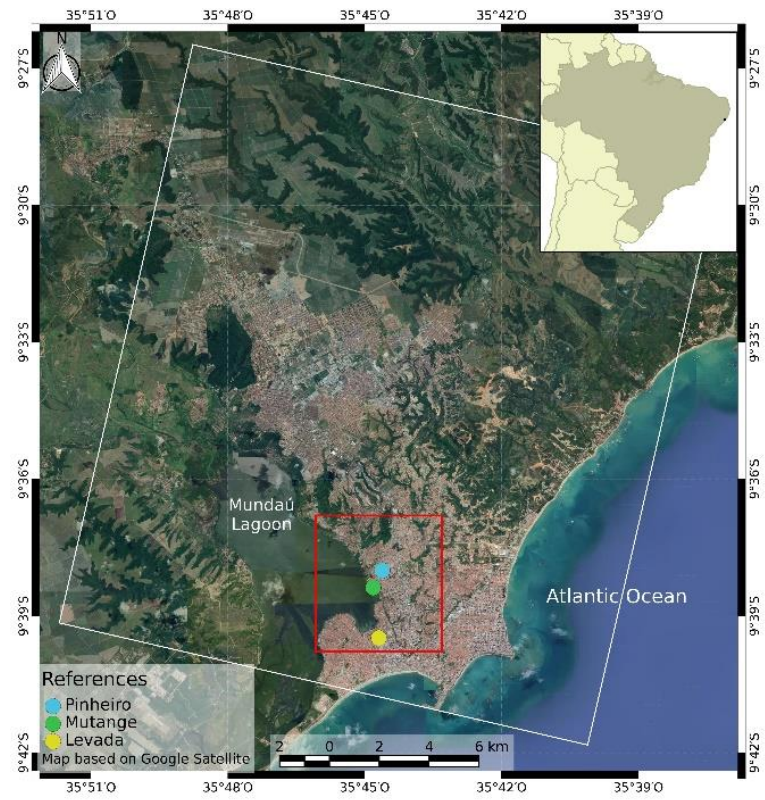

Figure 1. City of Maceió and area covered by the Sentinel 1 subswath (white polygon). Deformation results inside the red box where used by the inversion algorithm.

\section{DATASET AND PROCESSING}

We used a dataset of 81 scenes acquired by the Sentinel 1 constellation, between 04/2015 and 5/2019 in descending pass. The acquisition mode is the Interferometric Wide, with a look angle of $33.8^{\circ}$. The area processed is shown in Figure 1 (white polygon). The images series is not evenly distributed in time. First and second scenes were acquired in April 2015 and January 2016 , respectively. Then, since October 2016, there is one scene every 12 days.

Processing technique is the MT-DInSAR Small Baseline Subsets (SBAS) approach (Berardino et al., 2002). Maximum perpendicular baseline is under 300 meters, well below the critical one for the system. Temporal baseline ranges between 12 days and 600 days for the longest interferogram. The AOI is mostly covered by the city, so interferometric coherence remains high even at the longest time spans. Phase unwrapping was performed using the 3D algorithm proposed by (Pepe and Lanari, 2006). Multilooking factors of $2 \times 5$ (azimuth $x$ range) giving a ground resolution of $30 \times 20$ meters were applied to the interferograms, which allows removing most of the decorrelation noise while maintaining acceptable spatial resolution. In order to remove high frequency and atmospheric artifacts, the time-series were filtered by using a triangular window of 300 days length.

We performed the inversion of the mean velocity of deformation using the dMODELS package (Battaglia et al., 2013a). It assumes simple analytical sources embedded in an elastic half space. Employed sources are a spherical pressure one, a prolate shperoid, a sill-like source, and tensile, strike-slip and dip-slip rectangular dislocations (Battaglia et al., 2013b). dMODELS implements a weighted least-squares algorithm combined with a random search grid and the penalty function is the chi-square per degrees of freedom $\chi_{v}^{2}$. In order to lower the computational cost of the inversion, we subsampled the deformation data and used 1124 points inside the box displayed in Figure 1 (red box), and 256 random trials. Inversion results were compared using the Ftest proposed in (Battaglia and Hill, 2009), in order to see if the chi-square reduction is statistically significant.

\section{RESULTS}

Figure 2 shows the obtained SBAS processing results, in terms of deformation mean velocity and time series. Mean velocity does not capture eventual non linearity in the displacement series, but allows to understand the extension of the affected area. In our case, the observed pattern represents LOS (Line of Sight) enlarging, which is compatible with subsidence if horizontal components are negligible. We assume that this is the case, altough for ensuring the interpretation a second dataset acquired with different geometry should be available.
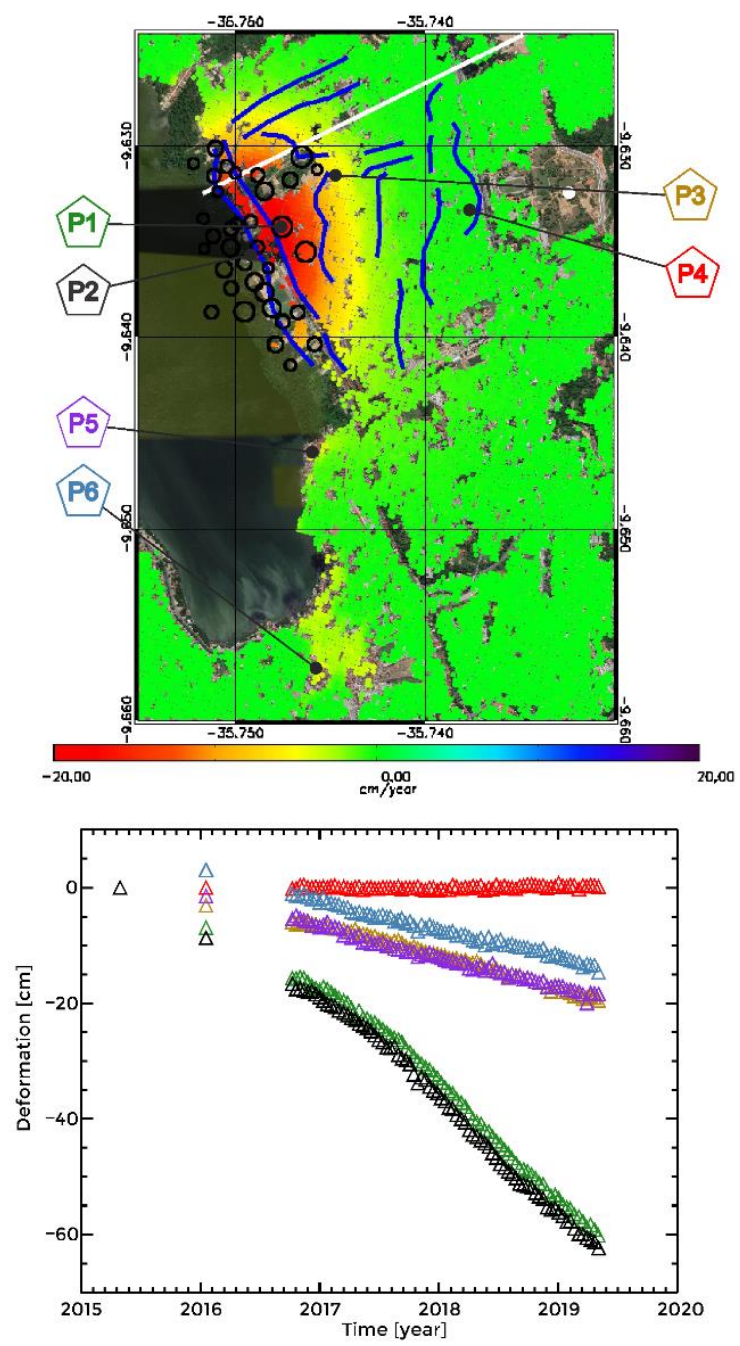

Figure 2. Mean velocity of deformation (top) and time series extracted at selected locations (bottom). Note that the first data in the time series is common for all of them, i.e. is the common origin for the displacements. White dot in the velocity map marks the location of the reference stable point. Black circles indicates the location of salt mining facilities (see discussion). Blue lines mark surface intersection of normal faults. 
Deformation concentrates in two areas. First one presents a semi circular pattern, of diameter $\sim 1.8 \mathrm{~km}$, centered in the Mundaú lagoon coast at Mutange neighborhood, and affecting the neighboring Pinheiro. Only the onshore part is visible, because no results can be obtained over the water surface due to temporal decorrelation. It reaches more than $60 \mathrm{~cm}$ cummulative subsidence, LOS projected, during the analyzed time span $(\mathrm{P} 1$ and P2 in Figure 2). During the first almost two years (2015 2016), no detail is visible due to lack of data. However subsidence is confirmed by the $9 \mathrm{~cm}$ jumps between the first and
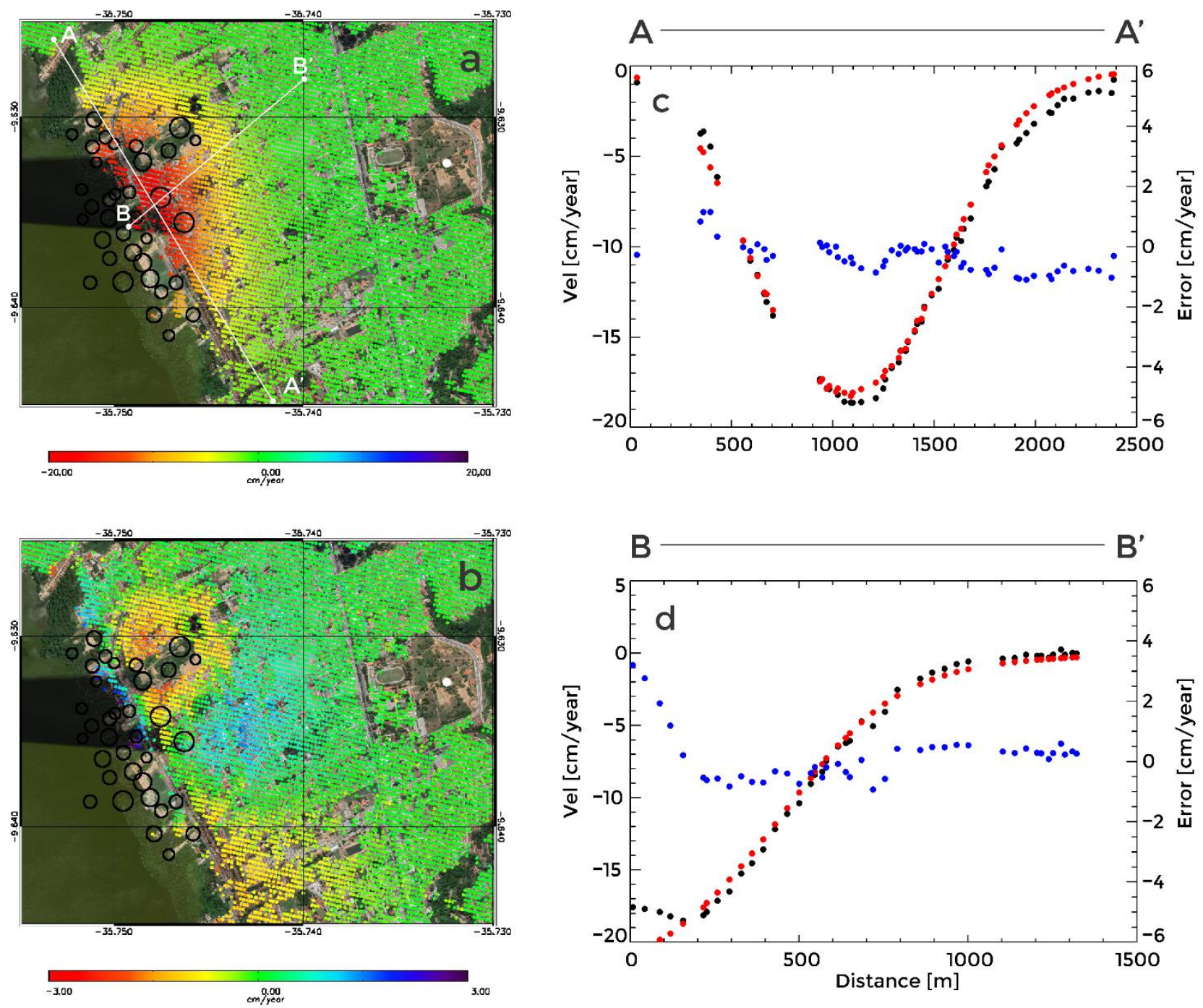

Figure 3. a) Deformation produced by a sill-like source characterized by the parameters of Table 1. b) Residuals between the modelled and measured deformation. c,d) profiles AA' and BB', respectively, of the modelled (red dots) and measured (black dots) deformation. Residuals are represented by the blue dots.

\begin{tabular}{|c|c|c|c|c|c|c|c|c|c|c|}
\hline Model & $\chi_{v}^{2}$ & $\begin{array}{c}\text { Lat } \\
(\mathrm{deg})\end{array}$ & $\begin{array}{c}\text { Long } \\
(\mathrm{deg})\end{array}$ & $\begin{array}{c}\text { Depth } \\
(\mathrm{km})\end{array}$ & $\begin{array}{c}\text { Radius } \\
(\mathrm{km})\end{array}$ & $\delta \mathrm{P}$ & $\begin{array}{c}\delta \mathrm{V} \\
\left(10^{6}\right. \\
\left.\mathrm{m}^{3} / \mathrm{yr}\right)\end{array}$ & $\mathrm{A}$ & $\begin{array}{c}\theta \\
(\mathrm{deg})\end{array}$ & $\begin{array}{c}\phi \\
(\mathrm{deg})\end{array}$ \\
\hline Sphere & 6.04 & -9.6345928 & -35.750916 & 0.437 & 0.1 & -0.07716 & -0.2431 & - & - & - \\
\hline Spheroid & 31.45 & -9.6359465 & -35.762398 & 1.267 & 0.1 & -0.983 & -1.48 & 0.68 & 28 & 1 \\
\hline Sill & 1.81 & -9.6354828 & -35.751469 & 0.399 & 0.784 & $-1.642 \mathrm{e}-4$ & -0.350807 & - & - & - \\
\hline
\end{tabular}

Table 1. Parameters of best fit spheroidal sources.

\begin{tabular}{|c|c|c|c|c|c|c|c|c|c|c|}
\hline Model & $\chi_{v}^{2}$ & $\begin{array}{c}\mathrm{x}_{\mathrm{i}} \\
(\mathrm{km})\end{array}$ & $\begin{array}{c}\mathrm{y}_{\mathrm{i}} \\
(\mathrm{km})\end{array}$ & $\begin{array}{c}\mathrm{X}_{\mathrm{f}} \\
(\mathrm{km})\end{array}$ & $\begin{array}{c}\mathrm{yf}_{\mathrm{f}} \\
(\mathrm{km})\end{array}$ & $\begin{array}{c}\mathrm{Z}_{\mathrm{t}} \\
(\mathrm{km})\end{array}$ & $\begin{array}{c}\mathrm{Zb} \\
(\mathrm{km})\end{array}$ & $\mathrm{U}$ & $\begin{array}{c}\delta \\
(\mathrm{deg})\end{array}$ & $\begin{array}{c}\phi \\
(\mathrm{deg})\end{array}$ \\
\hline Dip & 4.9 & 197.024 & 8934.004 & 198.433 & 8933.715 & 0.339 & 5.258 & -0.97 & 1 & 102 \\
\hline Strike & 6.67 & 198.526 & 8933.697 & 196.195 & 8923.773 & 0.268 & 13 & -0.79 & 1 & 193 \\
\hline Tensile & 25.67 & 199.196 & 8932.972 & 199.160 & 8932.932 & 0.318 & 25.3 & -1.34 & 1 & 222 \\
\hline
\end{tabular}

Table 2. Parameters of the best fit rectangular dislocation models. Dip, strike and tensile refers to the movement direction. Parameter $\mathrm{U}<0$ means normal, left lateral and closing motion. $\delta$ and $\phi$ are the inclination and strike direction, respectively. 
second, and between the second and third scenes. Between the start of the series, in April 2015 and middle 2017, subsidence shows a rate of near $10.7 \mathrm{~cm} /$ year at point $\mathrm{P} 2$. Then, since middle 2017 the process accelerates reaching a rate of $20 \mathrm{~cm} /$ year. Furthermore, note that the change between the point of maximum deformation velocity and a point of zero velocity is relatively smooth, evidenced in the figure by the colors gently fading from red to green.

Second deforming sector is in the Levada neighborhood, located south of the Mutange and Pinheiro ones. It shows also LOS lengthening, compatible with subsidence. In this case, the pattern shape is irregular, elongated $\sim 0.5 \mathrm{~km}$ in perpendicular direction to the coast. It reaches $10 \mathrm{~cm}$ cumulative deformation but, differently from the northern one, subsidence seems to begin at some point between January and October 2016 (P6 in Figure 2). In this case, the change in velocity is abrupt, i.e. there is no smooth transition between no deformation areas and deformation ones, particularly in the southern side of the pattern.

Modelling results are summarized in Tables 1 and 2. Best fitting source, i.e. the one of minor chi-square value, is the sill-like one. The fitting is very good, given that $91 \%$ of the modeled points show residuals with misfit lower than 1 standard deviation. Comparison between it and the spherical one, through the F-test, confirms that the chi-square reduction is significant, given the increment in the parameters. The other sources, spheroid and rectangular dislocations, have more parameters and higher chisquare than the sill-like one, so their fitting is clearly poorer. In particular, the spheroidal one can be discarded due to the high value in $\Delta \mathrm{P}$ parameter, which is incompatible with a linear elastic medium. In summary, the observed deformation is compatible with the stress field produced by a sill-like source, centered at $9.635^{\circ}$ lat. and $-35.751^{\circ}$ long., at a depth of $0.399 \mathrm{~km}$, and with a radius of $0.78 \mathrm{~km}$. Figure 3 shows the model deformation and residuals.

\section{DISCUSSION}

Regarding the main deformation spot, which is affecting Mutange and Pinheiro neighborhoods, cracks and differential sink are a known issue since long ago, but the phenomena intensified in March 2018. This motivated the CPRM to perform an extensive study under several hypotheses, which is summarized in (Serviço Geológico do Brasil (CPRM), 2019a). The hypotheses for explaining the observations were: geotechnical and constructive issues affecting the buildings; deforming underground caverns related with salt mining; active tectonics provoking displacement in faults; and groundwater exploitation.

First hypothesis is discarded by the interferometric results. For the CPRM, interferometric processing was done by the company Telespazio using a dataset of scenes acquired by the COSMOSkymed satellite (Goes et al., 2019a). Their results show essentially the same deformation pattern in Pinheiro and Mutange we independently obtained and described in the previous section. The remaining hypotheses point to a buried source so are compatible with the observed deformation pattern.

The third hypothesis, i.e. deformation linked to groundwater exploitation, is rapidly discarded because in the deforming area, groundwater levels actually recovered during the analyzed time span (Goes et al., 2019b).
The second hypothesis requires a deeper analysis. Salt is exploited in the area by dissolution using deep wells. The remaining cavities must be filled with a pressurized brine. They exploit the Maceió Formation, below $900 \mathrm{~m}$ depth. Location of the mines, shown in Figures 2 and 3 as black circles, are coincident with the deformation pattern, and some cavities show evidence of collapse and/or lack of the filling brine (Goes et al., 2019c, 2019d). Instead, our inverse modelling results fit the deformation source at $\sim 400 \mathrm{~m}$ depth (sill), $437 \mathrm{~m}$ (sphere), $\sim 339$ $\mathrm{m}$ (dip slip fault), which is not compatible with the caverns location. Additionally, the area is crossed by dip-slip faults. In particular the Mutange faults system (Figure 1), oriented in NNW-SSE direction at the lagoon coast, intercept some of the salt mining wells at depths of around 400 meters. According to (Serviço Geológico do Brasil (CPRM), 2019b), many wells show failure, casing collapse, or dog-legs near the transition between formations Marituba and Poçao, also below $400 \mathrm{~m}$ depth. In consequence, it seems possible that the observed deformation would be compatible with displacement in the normal faults crossing the area. This interpretation agrees with (Goes et al., 2019e), where the authors suggest that re-activation of the Mutange fault system could be linked to the salt exploitation through a change in the local stress field.

\section{CONCLUSIONS}

In this work we characterized significant subsidence affecting part of Maceió city in Brazil, with consequences in buildings and city infrastructure. We processed a dataset of Sentinel 1 SAR scenes, obtaining results that are compatible with the previously reported ones by the CPRM using another SAR sensor (COSMOSkymed). Given the nature of the observed phenomena, Sentinel spatial and temporal resolution is adequate for properly characterizing it. Furthermore, we remark that free availability of Sentinel 1 data allows to study this kind of cases at very low cost.

Modelled deformation field explains most of the observed displacements using a sill-like source located $\sim 400 \mathrm{~m}$ below the surface. Additional information provided by the CPRM points to re-activation of normal faults crossing the area. One remaining question is why the sill-like horizontal source fits so well the deformation pattern, even better than the dip-slip dislocation. We envision two aspects that could be misleading the results: 1) the complete deformation pattern is not observable, but only a reduced part of it and 2) modelling using one LOS component not always correctly constrains the source, particularly in the case of models where the orientation is important. First problem could be solved creating artificial coherent targets over the lagoon, but at a relatively high cost. Second one could be solved by combining ascending and descending passes of the same or even different sensors.

As can be noted, the discussed results refer to the most prominent deformation pattern. Instead, little attention has been given to the process affecting the Levada neighborhood. Modelling of that pattern should be done independently, because it is somewhat distant from the other one, and causes could be rather different. We hope to address this work in the near future. 


\section{ACKNOWLEDGEMENTS}

We acknowledge Dr. Alejandro Frery for providing the motivation for this work.

\section{REFERENCES}

Battaglia, M., Alpala, J., Alpala, R., Angarita, M., Arcos, D., Euillades, L., Euillades, P., Muller, C., Narváez, L., 2019. Monitoring Volcanic Deformation, in: Reference Module in Earth Systems and Environmental Sciences. Elsevier, p. B9780124095489110000. https://doi.org/10.1016/B978-0-12409548-9.10902-9

Battaglia, M., Cervelli, P.F., Murray, J.R., 2013a. dMODELS: A MATLAB software package for modeling crustal deformation near active faults and volcanic centers. J. Volcanol. Geotherm. Res. 254, 1-4. https://doi.org/10.1016/j.jvolgeores.2012.12.018

Battaglia, M., Cervelli, P.F., Murray, J.R., 2013b. Modeling crustal deformation near active faults and volcanic centers-A catalog of deformation models. US Geol. Surv. Tech. Methods 13-B1.

Battaglia, M., Hill, D.P., 2009. Analytical modeling of gravity changes and crustal deformation at volcanoes: The Long Valley caldera, California, case study. Tectonophysics 471, 45-57. https://doi.org/10.1016/j.tecto.2008.09.040

Berardino, P., Fornaro, G., Lanari, R., Sansosti, E., 2002. A New Algorithm for Surface Deformation Monitoring Based on Small Baseline Differential SAR Interferograms. IEEE Trans. Geosci. Remote Sens. 40, 2375-2383.

Carlà, T., Intrieri, E., Raspini, F., Bardi, F., Farina, P., Ferretti, A., Colombo, D., Novali, F., Casagli, N., 2019. Perspectives on the prediction of catastrophic slope failures from satellite InSAR. Sci. Rep. 9, 14137. https://doi.org/10.1038/s41598-019-50792-y

Euillades, L.D., Euillades, P.A., Riveros, N.C., Masiokas, M.H., Ruiz, L., Pitte, P., Elefante, S., Casu, F., Balbarani, S., 2016. Detection of glaciers displacement time-series using SAR. Remote Sens. Environ. 184, 188-198. https://doi.org/10.1016/j.rse.2016.07.003

Feng, W., Samsonov, S., Tian, Y., Qiu, Q., Li, P., Zhang, Y., Deng, Z., Omari, K., 2017. Surface deformation associated with the $2015 \mathrm{M} \mathrm{w} 8.3$ Illapel earthquake revealed by satellite-based geodetic observations and its implications for the seismic cycle. Earth Planet. Sci. Lett. 460, 222-233. https://doi.org/10.1016/j.epsl.2016.11.018

Goes, H., Fernandes da Silva, S., Antonelli, T., 2019a. Estudos sobre a Instabilidade do Terreno nos Bairros Pinheiro, Mutange e Bebedouro, Maceió (AL). Volume II Geofísica - Sismologia. Brasilia.

Goes, H., Fernandes da Silva, S., Antonelli, T., 2019b. Estudos sobre a Instabilidade do Terreno nos Bairros Pinheiro, Mutange e Bebedouro, Maceió (AL). Volume II Hidrogeologia. Brasilia.

Goes, H., Fernandes da Silva, S., Antonelli, T., 2019c. Estudos sobre a Instabilidade do Terreno nos Bairros Pinheiro, Mutange e Bebedouro, Maceió (AL). Volume II Geofísica - Integração de dados geológicos e de extração de sal em ambiente 3D. Brasilia.

Goes, H., Fernandes da Silva, S., Antonelli, T., 2019d. Estudos sobre a Instabilidade do Terreno nos Bairros Pinheiro, Mutange e Bebedouro, Maceió (AL). Volume II Geofísica Audiomagnetotelurico. Brasilia.
Goes, H., Fernandes da Silva, S., Antonelli, T., 2019e. Estudos sobre a Instabilidade do Terreno nos Bairros Pinheiro, Mutange e Bebedouro, Maceió (AL). Volume II Geofísica - gravimetria. Brasilia.

Hoffmann, D., Zebker, H., Galloway, D., F. Amelung, 2001. Seasonal subsidence and rebound in Las Vegas Valley, Nevada, observed by synthetic aperture radar interferometry. Water Resour. Res. 37, 1551-1566.

Hooper, A., Bekaert, D., Spaans, K., Arıkan, M., 2012. Recent advances in SAR interferometry time series analysis for measuring crustal deformation. Tectonophysics 514-517, 1-13. https://doi.org/10.1016/j.tecto.2011.10.013

Kim, J.-W., Lu, Z., 2018. Association between localized geohazards in West Texas and human activities, recognized by Sentinel-1A/B satellite radar imagery. Sci. Rep. 8. https://doi.org/10.1038/s41598-018-23143-6

P. Potin, B. Rosich, N. Miranda, P. Grimont, I. Shurmer, A. O Connell, M. Krassenburg, J. Gratadour, 2018. Sentinel-1 Constellation Mission Operations Status, in: IGARSS 2018 2018 IEEE International Geoscience and Remote Sensing Symposium. Presented at the IGARSS 2018 - 2018 IEEE International Geoscience and Remote Sensing Symposium, pp. 1547-1550. https://doi.org/10.1109/IGARSS.2018.8517743

Pepe, A., Lanari, R., 2006. On the Extension of the Minimum Cost Flow Algorithm for Phase Unwrapping of Multitemporal Differential SAR Interferograms. IEEE Trans. Geosci. Remote Sens. 44, 2374-2383.

Samsonov, S.V., González, P.J., Tiampo, K.F., D’Oreye, N., 2014. Modeling of fast ground subsidence observed in southern Saskatchewan (Canada) during 2008-2011. Nat. Hazards Earth Syst. Sci. 14, 247-257. https://doi.org/10.5194/nhess-14-2472014

Serviço Geológico do Brasil (CPRM), 2019a. Estudos sobre a Instabilidade do Terreno nos Bairros Pinheiro, Mutange e Bebedouro, Maceió (AL). Volume I Relatório Síntese dos Resultados $\mathrm{N}^{\circ} 1$. Brasilia.

Serviço Geológico do Brasil (CPRM), 2019b. Estudos sobre a Instabilidade do Terreno nos Bairros Pinheiro, Mutange e Bebedouro, Maceió (AL). Respostas do Serviço Geológico do Brasil aos Questionamentos da Braskem. Brasilia. 